\title{
Parental Drinking, Mental Health, and Education; The Association with Offspring's Recurring contact with Healthcare Services for Anxiety/Depression. A longitudinal Combined HUNT Survey and Health Registry Study
}

Ingunn Lund ( $\square$ ingunnolea@gmail.com )

Norwegian Institute of Public Health

Njål Andersen

BI Norwegian Business School

Marte Handal

Norwegian Institute of Public Health

Helga Ask

Norwegian Institute of Public Health

Svetlana Skurtveit

Norwegian Institute of Public Health

Eivind Ystrom

PROMENTA Research Center, Department of Psychology, University of Oslo Jasmina Burdzovic Andreas

Norwegian Institute of Public Health

\section{Research Article}

Keywords: Longitudinal study, Parental drinking, Parental mental health, Alcohol, Socioeconomic status, Anxiety, Depression

Posted Date: February 25th, 2021

DOI: https://doi.org/10.21203/rs.3.rs-237218/v1

License: (c) (1) This work is licensed under a Creative Commons Attribution 4.0 International License.

Read Full License 


\section{Abstract}

Background and aims: Previous research have shown that certain risk constellations of parental drinking, mental health, and years of education were prospectively associated with increased risk of offspring receiving a diagnosis and/or treatment for anxiety/depression. We know less about how such constellations may relate to other aspects of offspring's mental health -- including recurring healthcare utilization. We examined offspring's recurring utilization of healthcare services for these disorders, as measured both by the duration of and the number of contacts with services during a 7-year study period, as a function of parental risk constellations.

Design: Longitudinal cohort design combining health survey and registry data.

Participants and setting: The sample included 8773 offspring from 6696 two-parent families who participated in the Nord-Trøndelag Health Study in Norway.

Measurements: The exposures were five constellations of parental risks, derived previously from latent profile analysis, characterized by drinking frequencies and quantities, years of education, and mental health. The outcomes were the number of years in contact with, and the total number of contacts with the healthcare services for anxiety/depression in offspring as recorded in healthcare registries during 20082014. Associations were examined using zero-inflated negative binomial regression models while accounting for demographics and offspring's early mental health.

Results: Parental risk constellations were not significantly associated with offspring's' recurring use of healthcare services for anxiety and depression during the study period, neither in terms of the number of utilization years or the number of contacts. These were primarily a function of offspring's own characteristics, such as male gender and early mental health problems.

Conclusions: Parental risk constellations were not prospectively associated with recurring utilization of healthcare services for anxiety and depression disorders among the offspring during the 7-year study period; offspring from 4 risky constellations were no more likely to use such services for longer period of time or to use them on more occasions than offspring from the low-risk constellation. Seen in conjunction with previous research, parental risk constellations may be thus more informative for understanding the etiology of offspring's anxiety/depression, than for understanding of other aspects, including recurrence of healthcare utilization in offspring.

\section{Introduction}

Anxiety and depression are common mental disorders (1-3), and leading causes of disability globally (4). These disorders negatively affect the afflicted individuals in multiple ways; how they eat and sleep; their relationships with family and friends; their physical health; and performance and attrition in school and at work. Given the high prevalence and the severe personal and societal consequences of anxiety and depression, understanding not just the etiology but also the course of these disorders is informative for 
prevention and treatment strategies. This implies research focusing not only on the risk of these disorders but also on their additional characteristics, such as their recurrence or duration. Our previous study showed that offspring's exposure to certain constellations of parental risk factors - specifically low education in both parents and elevated drinking ) in both parents, and symptoms of mental health problems in fathers - was prospectively associated with their increased risk for receiving a diagnosis and/or treatment for anxiety/depression during the study period (5). Whether or not such associations exist for additional aspects of anxiety/depression in offspring - specifically, their recurrence - was the focus of this paper.

The literature on the association between parental risk factors and the recurrence of offspring mental health problems remains scarce and has yielded mixed results; some studies suggest an association (6, 7 ), while others do not (8-10). For instance, some research has shown and association between parental education and the episode duration and recurrence of anxiety in offspring, (7); and between parental psychopathology and the episode duration and recurrence of mood and anxiety disorders (6). Conversely, other research showed that parental psychopathology and substance abuse were associated with the onset of anxiety and depression, but that the association did not extend to the recurrence the disorder (8). Similarly, another study found that parental psychopathology was associated with onset of offspring social phobia, but not proportion of years affected (9). In a 20-year follow-up study, offspring of depressed parents were three times more likely to experience depression compared to offspring of nondepressed parents. However, within offspring with a registered depression, there were no difference in the the number of, duration of, and the percentage of time in depressive episodes - between offspring of depressed and non-depressed parents (10).

The abovementioned studies utilized a life history approach or clinical interviews, and they form the basis of the current knowledge of the association between parental risk factors and recurrence of anxiety/depression in offspring. We aim to contribute to and extend this knowledge base by utilizing a different approach and by providing an additional perspective. Specifically, instead of retrospective life histories, we prospectively combine information from general population health survey with health registries that capture all contact that offspring had with primary and specialist health care for anxiety/depression over seven years. Healthcare utilization literature has shown that individuals with severe anxiety and depression tend to utilize healthcare services more frequently - both for healthcare services in general, and mental healthcare services in particular - compared to those with less severe problems (11-13). Based on this line of research, we use number of years in contact with, and number of contacts with healthcare services for anxiety and depression disorders as an indicator of disorder recurrence. Throughout the manuscript, when we refer contact with the healthcare services, we refer to only contacts for anxiety and depression.

Parental drinking, mental health, and socio-economic status (SES) are all associated with increased risk of mental health problems in offspring $(10,14-19)$. Common limitations in previous research include focus on a single parental risk factor (20), use of cross-sectional study design (8), and examination of clinical-level parental risk factors only $(14,21)$. Consequently, past studies failed to detect risk factors 
that may present below-clinical levels or in (accumulated) combinations with one another. Further, many studies only include information on one parent often provided by offspring (22). We address these shortcomings in three ways. First, we use a community sample with information from mothers, fathers, and offspring. Second, as our substantive exposure, we use constellations of parental risk factors (alcohol drinking frequency and amount, education, and mental health of both parents) as they naturally occurred in families (5). Third, we use a prospective study design that captures outcomes of interest with practically no attrition (23); offspring were followed up through 2 continually updated health registries providing information about all contacts with primary and specialist healthcare for anxiety/depression.

We examine the prospective association between parental risk constellations and offspring's recurrence of anxiety/depression, measured as the number of years in contact and number of contacts with health care services, during the 7-year study period (2008 and 2014). The findings can improve our understanding and offer valuable nuance to the knowledge of whether parental risk constellations are - in addition to being associated with risk of offspring anxiety/depression - also associated with disorder recurrence.

\section{Methods}

\section{Design and sample}

We combined previously collected survey data from the Nord-Trøndelag Health Studies (HUNT/YoungHUNT) with prospectively collected health registry data, where HUNT surveys provided information on substantive exposures and covariates and health registries provided information on substantive outcomes of interest. Data sources were linked at the individual using person identification numbers assigned to all residents in Norway.

HUNT and Young-HUNT are large longitudinal general population studies covering a range of healthrelated topics, where all adults older than 20 and all adolescents between 13 and 20 years of age residing in Nord-Trøndelag county in Norway were invited to participate in these studies, respectively (24-26). The demographic structure of the county is reasonably representative of the Norwegian population (24-26).

We used data from two waves, collected in 1995-97, and 2006-08. The response rates for the surveys used ranged from $54.1-82.7 \%(24,25)$. Detailed information on response rates, how nonparticipation was handled, and reasons for nonparticipation has been provided in HUNT and young-HUNT cohort description manuscripts (24-27). HUNT surveys provided information on parents, while Young-HUNT provided information on offspring; parents and offspring completed their HUNT questionnaires at approximately the same time and their responses were linked at the family level using the unique family numbers available from Statistics Norway. Because our aim was to examine the associations between exposures and outcomes in a sample that was not affected by a range of other risk factors - such as single-parent families - other potential risks were eliminated by study design and through the inclusion criteria focusing on 2-parent families only. Our analytical sample therefore consisted of family triads ( $\mathrm{N}=$ $6,696)$ where the all age-eligible offspring $(N=8,773)$ and both parents had completed the surveys. All 
offspring were 13-19 years old when they participated in Young-HUNT and 14-33 years old in 2008 when registry follow-up started.

\section{Ethics}

Study participants provided informed consent. The study was approved by the Norwegian Data Protection Authority (\# 38949) and the Regional Committees for Medical and Health Research Ethics (\#2014/867). All procedures were performed in accordance with the relevant guidelines and regulations of these review boards.

\section{Measures}

\section{Exposures}

The primary exposure was based on previously identified constellations of maternal and paternal risk factors: education, drinking frequency and amount, and mental health (5). In the HUNT survey, the items: "How many times a month do you normally drink alcohol?" and "How many glasses of beer, wine, or spirits do you usually drink in the course of two weeks?" captured maternal and paternal drinking frequency and quantity respectively. Parental mental health symptoms were measured with the Hospital Anxiety and Depression Scale (HADS), where both parents completed the HADS scale as part of the HUNT survey $(28,29)$. HADS is commonly used to screen for anxiety and depression, where the summed scale scores translate to the following diagnostic categories 0-7 normal, 8-10 indicate mild symptoms; 11-14 moderate symptoms; and 15-21 severe symptoms (28). The number of years of completed education for each parent was obtained from Statistics Norway.

Based on these indicators, we previously identified five mutually exclusive risk constellations (5) using a Latent Profile Analysis (LPA) $(30,31)$. Table 1 provides a conceptual overview of these Latent Profiles (LP). In short, LP1 was characterized by low education for both parents, but otherwise no risk. LP2 was characterized by multiple risks; low education, mental health symptoms within a mild disorder range, and weekly binge drinking in both parents. LP3 was characterized by the lowest overall risk: some higher education, good mental health, and infrequent low-quantity drinking in both parents. In LP4, casual weekly drinking in both parents was the only potential risk factor. LP5 was characterized by multiple risk factors: frequent and high quantity drinking in both parents and mental health symptoms indicative of a mild disorder in fathers. We have previously shown increased risk for anxiety and depression diagnosis or treatment among offspring from risk constellations LP1 (i.e., low education in both parents) and LP5 (elevated drinking frequency and quantity in both parents, and elevated mental health symptoms in fathers)(5). 
Table 1

Description of the parental risk constellations (Latent Profiles)

\begin{tabular}{|c|c|c|c|c|c|}
\hline & $\begin{array}{l}\text { Latent } \\
\text { profile } 1\end{array}$ & Latent profile 2 & $\begin{array}{l}\text { Latent } \\
\text { profile } \\
3\end{array}$ & $\begin{array}{l}\text { Latent } \\
\text { profile } 4\end{array}$ & Latent profile 5 \\
\hline Characteristic & $\begin{array}{l}\text { Low } \\
\text { Education }\end{array}$ & $\begin{array}{l}\text { Multiple risks: binge } \\
\text { drinking and mental } \\
\text { health symptoms in } \\
\text { both parents }\end{array}$ & $\begin{array}{l}\text { Low } \\
\text { overall } \\
\text { risk }\end{array}$ & $\begin{array}{l}\text { Casual } \\
\text { drinking } \\
\text { in both } \\
\text { parents }\end{array}$ & $\begin{array}{l}\text { Multiple risks: } \\
\text { frequent drinking } \\
\text { both parents, mental } \\
\text { health symptoms } \\
\text { fathers }\end{array}$ \\
\hline \multicolumn{6}{|l|}{$\begin{array}{l}\text { Participants, } \\
n(\%)\end{array}$} \\
\hline Family ${ }^{a}$ & $\begin{array}{l}4,857 \\
(69.1 \%)\end{array}$ & $194(2.8 \%)$ & $\begin{array}{l}1,444 \\
(20.5 \%)\end{array}$ & $\begin{array}{l}473 \\
(6.7 \%)\end{array}$ & $61(.9 \%)$ \\
\hline Children & $\begin{array}{l}5,966 \\
(68.0 \%)\end{array}$ & $246(2.8 \%)$ & $\begin{array}{l}1,884 \\
(21.5 \%)\end{array}$ & $\begin{array}{l}598 \\
(6.8 \%)\end{array}$ & $79(.9 \%)$ \\
\hline \multicolumn{6}{|l|}{$\begin{array}{l}\text { Education } \\
\text { (years) }^{\mathrm{b}}\end{array}$} \\
\hline Maternal & $<12$ & $<12$ & $>12$ & $>12$ & $>12$ \\
\hline Paternal & $<11$ & $<12$ & $>14$ & $>12$ & $>12$ \\
\hline \multicolumn{6}{|l|}{$\begin{array}{l}\text { Maternal } \\
\text { drinking } \\
\text { (weekly) }\end{array}$} \\
\hline $\begin{array}{l}\text { Average } \\
\text { quantity }\end{array}$ & 1 drink & 3.92 drinks & $\begin{array}{l}1.25 \\
\text { drinks }\end{array}$ & $\begin{array}{l}4.1 \\
\text { drinks }\end{array}$ & 6.5 drinks \\
\hline $\begin{array}{l}\text { Average } \\
\text { frequency }\end{array}$ & 0.4 days & 0.95 days & $\begin{array}{l}0.5 \\
\text { days }\end{array}$ & $\begin{array}{l}2.3 \\
\text { days }\end{array}$ & 5.4 days \\
\hline
\end{tabular}

Notes: The original Latent profile analysis procedures utilized all indicators in their original format(5); to aid interpretation, we re-scaled the estimates to show average weekly drinking quantities and frequencies. Elevated levels of parental risk factors are shown in bold. aSome families had multiple children, therefore the number of children is greater than the number of families for each LP. ${ }^{b}$ From the Statistics Norway records. ${ }^{\mathrm{C}}$ From parental self-reports. ${ }^{\mathrm{d}}$ Quantity $=$ number of glasses of beer, wine, or liquor reported in HUNT surveys. ${ }^{e}$ HADS (14-item Hospital Anxiety and Depression Scale) is commonly used to screen for anxiety and depression. Sum scores translate to the following diagnostic categories: 0-7 normal, 8-10 mild, 11-14 moderate, and 15-21 severe symptoms. 


\begin{tabular}{|c|c|c|c|c|c|}
\hline & $\begin{array}{l}\text { Latent } \\
\text { profile } 1\end{array}$ & Latent profile 2 & $\begin{array}{l}\text { Latent } \\
\text { profile } \\
3\end{array}$ & $\begin{array}{l}\text { Latent } \\
\text { profile } 4\end{array}$ & Latent profile 5 \\
\hline \multicolumn{6}{|l|}{$\begin{array}{l}\text { Paternal } \\
\text { drinking } \\
\text { (weekly) }{ }^{c, d}\end{array}$} \\
\hline $\begin{array}{l}\text { Average } \\
\text { quantity }\end{array}$ & 2 drinks & 11.2 drinks & $\begin{array}{l}2.3 \\
\text { drinks }\end{array}$ & $\begin{array}{l}4.8 \\
\text { drinks }\end{array}$ & 6.6 drinks \\
\hline $\begin{array}{l}\text { Average } \\
\text { frequency }\end{array}$ & 0.7 days & 1.9 days & $\begin{array}{l}0.9 \\
\text { days }\end{array}$ & 2 days & 3 days \\
\hline \multicolumn{6}{|c|}{$\begin{array}{l}\text { Mental health } \\
\text { (HADS } \\
\text { Score) } \\
\text { c, e }\end{array}$} \\
\hline Maternal & $\begin{array}{l}\text { Normal } \\
\text { range }\end{array}$ & Mild symtoms & $\begin{array}{l}\text { Normal } \\
\text { range }\end{array}$ & $\begin{array}{l}\text { Normal } \\
\text { range }\end{array}$ & Normal range \\
\hline Paternal & $\begin{array}{l}\text { Normal } \\
\text { range }\end{array}$ & Mild symptoms & $\begin{array}{l}\text { Normal } \\
\text { range }\end{array}$ & $\begin{array}{l}\text { Normal } \\
\text { range }\end{array}$ & Mild symptoms \\
\hline \multicolumn{6}{|c|}{$\begin{array}{l}\text { Notes: The original Latent profile analysis procedures utilized all indicators in their original format(5); } \\
\text { to aid interpretation, we re-scaled the estimates to show average weekly drinking quantities and } \\
\text { frequencies. Elevated levels of parental risk factors are shown in bold. a }{ }^{a} \text { Some families had multiple } \\
\text { children, therefore the number of children is greater than the number of families for each LP. }{ }^{b} \text { From } \\
\text { the Statistics Norway records. }{ }^{C} \text { From parental self-reports. }{ }^{d} \text { Quantity = number of glasses of beer, } \\
\text { wine, or liquor reported in HUNT surveys. }{ }^{e} \text { HADS (14-item Hospital Anxiety and Depression Scale) is } \\
\text { commonly used to screen for anxiety and depression. Sum scores translate to the following } \\
\text { diagnostic categories: } 0-7 \text { normal, } 8-10 \text { mild, } 11-14 \text { moderate, and } 15-21 \text { severe symptoms. }\end{array}$} \\
\hline
\end{tabular}

\section{Covariates}

We included the following covariates: age at Young-HUNT participation, age at start of registry follow-up in 2008, and gender. We also included a measure of early mental health symptoms as self-reported in the Young-HUNT survey by the participants on the 5-item Hopkins Symptoms Checklist (SCL-5) (32). In line with previous reports, SCL- 5 scores were categorized to reflect the top $25 \%$ of the distribution vs. rest ( 5 , $32,33)$, while missing responses $(n=138)$ were modeled as a separate category to prevent loss of data.

We included the following covariates: age at Young-HUNT participation, age at start of registry follow-up in 2008, and gender. We also included a measure of early mental health symptoms as self-reported in the Young-HUNT survey by the participants on the 5-item Hopkins Symptoms Checklist (SCL-5) (32). In line with previous reports, SCL-5 scores were categorized to reflect the top $25 \%$ of the distribution vs. rest (5, $32,33)$, while missing responses $(n=138)$ were modeled as a separate category to prevent loss of data.

We included the following covariates: age at Young-HUNT participation, age at start of registry follow-up in 2008, and gender. We also included a measure of early mental health symptoms as self-reported in the Young-HUNT survey by the participants on the 5-item Hopkins Symptoms Checklist (SCL-5) (32). In line 
with previous reports, SCL-5 scores were categorized to reflect the top $25 \%$ of the distribution vs. rest (5, $32,33)$, while missing responses $(n=138)$ were modeled as a separate category to prevent loss of data.

\section{Outcomes}

Information on our substantive outcomes of interest - that is, the recurrence of anxiety and depression over the 7-year study period - were obtained from the Norwegian primary- and specialist health registries where all contacts with primary and specialist health care services for all somatic and psychiatric conditions are recorded at the patient-level. In this study we used registry records in the primary and specialist healthcare services that included anxiety/depression codes, recorded annually between 2008 and 2014. Table 2 gives an overview of the included diagnostic codes from the International Classification of Primary Care (ICPC) and International Statistical Classification of Diseases and Related Health Problems 10th Revision (ICD-10). We examined two related outcomes; 1 ) the total number of calendar years the offspring were in contact with the healthcare services. This was calculated based on an individual's contacts with the health care services during each calendar year. 2) The total number of offspring's contacts with the healthcare services for anxiety/depression during the study period (20082014). Both outcomes were based on the combined primary and specialist healthcare registry records.

Table 2

Codes for anxiety and depression, as identified in the primary and specialist healthcare registries

\section{Registry for primary healthcare ${ }^{a}$ \\ Registry for specialist healthcare}

ICPC codes $^{\mathrm{C}} \quad$ ICD-10 codes $^{\mathrm{d}}$

$\begin{array}{llll}\text { P01 } & \begin{array}{l}\text { Feeling } \\ \text { anxious/nervous/tense }\end{array} & \begin{array}{l}\text { F30 } \\ \text { F39 }\end{array} & \text { Mood (affective) disorders } \\ & & \text { F03 } & \\ \text { P0eling depressed } & \text { F40 } & \begin{array}{l}\text { Anxiety, dissociative, stress-related, somatoform, and other } \\ \text { non-psychotic mental disorders }\end{array} \\ & & \text { F48 } & \end{array}$

P73 Affective psychosis

P74 Anxiety

disorder/anxiety state

P76 Depressive disorder

P79 Phobia/compulsive disorder

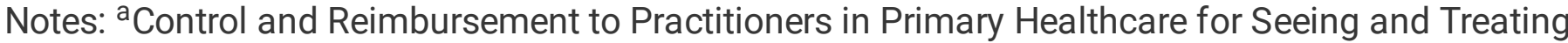
Patients' Database (CPHR). ${ }^{\mathrm{b}}$ The Norwegian Patient Registry (NPR). ${ }^{\mathrm{C}} \mathrm{CPC}=$ International Classification of Primary Care. ${ }^{\mathrm{I}} \mathrm{ICD} 10=$ International Statistical Classification of Diseases and Related Health Problems 10th Revision. 
As the number of a) years in contact with, and b) of actual contacts with the healthcare services for anxiety and depression are technically counts, and as the majority of our participants were not registered as having contact with the healthcare services for these problems (i.e., there was an excess of "zeros" in our data), our primary analysis was a count regression model, specifically, zero-inflated negative binomial (ZINB) regression. As zero-inflated models address both zero-inflation and over-dispersion problems, they are well-suited for mental health services research where studied outcomes often have low-prevalence rates $(34,35)$.

ZINB models consist of two components; the first models "zeroes" (the likelihood of no contact with the healthcare services in our case), while the second one models counts (the number of years, and the number of actual contacts with the healthcare services for anxiety and depression problems in our case). Thus, a ZINB model was estimated for each one of our outcomes, where the count components of these models specifically address our substantive questions of disorder(s) recurrence; that is, the duration of, and number of repeated contacts with the healthcare system for anxiety and depression disorders. Identical sets of predictors were included in the zero-inflated and the count component; the key exposure (parental risk constellations) was modeled as a categorical variable with the low-risk group, LP3, as the reference. To aid in the results interpretation, we reported the adjusted odds ratios (aORs) of no contact versus contact with the healthcare services for the zero-inflated component, and the adjusted incidence rate ratios (alRRs) for the count component of both models.

All analyses were conducted in Stata using the -zinb command (36), where robust standard errors were estimated based on family-level clusters using the $v c e$ (cluster) option. All estimates were thus adjusted for within-family nesting (37) .

\section{Results}

Most participants (81.5\%) did not have any record for anxiety or depression during the study follow-up period of 2008-2014. During that time, they were in contact with healthcare services for these disorders for just under half a year $(M=.43, S D=1.15)$, and 4 times $(M=3.7, S D=17.0)$ on average. For those $18.5 \%$ who had at least one contact with the healthcare system, the average number of years in contact was 2.34 (SD = 1.65; Min = 1, Max = 7), and the average number of contacts was 19.95 (SD = 35.16; Min = 1, Max $=478$ ) during the 7-year follow-up. Table 3 shows the distribution of main outcomes across the risk profiles, both for the entire sample and for those in contact with the healthcare system only. 
Table 3

Descriptives for primary outcomes across latent profiles (LP)

\begin{tabular}{|c|c|c|c|c|}
\hline \multirow[t]{4}{*}{ LP } & \multicolumn{2}{|c|}{$\begin{array}{l}\text { Number of years in contact with healthcare } \\
\text { services for anxiety/depression (2008-14) }\end{array}$} & \multicolumn{2}{|c|}{$\begin{array}{l}\text { Number of contacts with healthcare } \\
\text { services for anxiety/depression (2008-14) }\end{array}$} \\
\hline & Entire sample & With contacts only & Entire sample & With contacts only \\
\hline & $N=8,773$ & $n=1,624$ & $N=8,773$ & $n=1,624$ \\
\hline & $M(\mathrm{SD})$ & $M(\mathrm{SD})$ & $M(\mathrm{SD})$ & $M(\mathrm{SD})$ \\
\hline LP1 & $0.45(1.2)$ & $2.31(1.6)$ & $3.68(16.7)$ & $19.0(33.9)$ \\
\hline LP2 & $0.46(1.2)$ & $2.38(1.6)$ & $3.17(11.4)$ & $16.3(21.5)$ \\
\hline LP3 & $0.41(1.2)$ & $2.41(1.7)$ & $3.88(18.4)$ & $22.68(39.4)$ \\
\hline LP4 & $0.37(1.1)$ & $2.68(1.8)$ & $3.54(17.9)$ & $25.2(41.7)$ \\
\hline LP5 & $0.43(1.0)$ & $2.13(1.2)$ & $2.73(10.0)$ & $13.5(19.1)$ \\
\hline
\end{tabular}

Table 4 shows the results from the two fully adjusted ZINB regression models, with years in healthcare services (Model 1) and contacts with healthcare services (Model 2) for anxiety and/or depression as the examined outcomes. The results from both models show that LP1 (Low parental education) was associated with significantly lower odds of not having any healthcare contact for anxiety/depression during the study period (zero-inflation component) when compared to the low-risk group (LP3). That is, offspring from LP1 were more likely to have contact with healthcare services. However, parental risk constellations were not significantly associated with the count components in either of the models; that is, with the measures of anxiety and depression recurrence during the study period.

The most salient risk factor for both the number of years spent in and the number of visits to the healthcare services for anxiety/depression, was the offspring's own mental health symptomatology as self-reported during Young-HUNT participation. A similar pattern was observed for gender. Specifically, in relation to the substantive questions of recurring anxiety and depression; the top 25 percentile of SCL-5 scores distribution and female gender were both significantly associated with greater duration of and frequency of contacts with healthcare services (count components). 
Table 4

Number of years, and number of contacts with primary and specialist healthcare for anxiety/depression (2008-2014)

\begin{tabular}{|c|c|c|c|c|}
\hline \multirow[t]{3}{*}{ Variables } & \multicolumn{2}{|c|}{$\begin{array}{l}\text { Model 1: } \\
\text { Number of years in contact with } \\
\text { healthcare services for } \\
\text { anxiety/depression (2008-14) }\end{array}$} & \multicolumn{2}{|c|}{$\begin{array}{l}\text { Model 2: } \\
\text { Number of contacts with healthcare } \\
\text { services for anxiety/depression } \\
(2008-14)\end{array}$} \\
\hline & Zero-Inflated & Count & Zero-Inflated & Count \\
\hline & aOR $(95 \% \mathrm{Cl})^{b}$ & $\operatorname{alRR}(95 \% \mathrm{CI})^{\mathrm{c}}$ & $\mathrm{aOR}(95 \% \mathrm{Cl})^{\mathrm{b}}$ & $\operatorname{alRR}(95 \% \mathrm{Cl})^{c}$ \\
\hline Gender (M) & $1.76(1.47-2.01)$ & $0.87(0.79-0.98)$ & $1.88(1.53-2.29)$ & $0.64(0.50-0.81)$ \\
\hline $\begin{array}{l}\text { Age at Young- } \\
\text { HUNT }\end{array}$ & $1.07(1.03-1.12)$ & $0.98(0.94-1.01)$ & $1.11(1.04-1.17)$ & $0.97(0.91-1.03)$ \\
\hline Age in 2008 & $0.97(0.96-0.98)$ & $1.03(1.02-1.05)$ & $0.95(0.93-0.97)$ & $1.03(1.01-1.05)$ \\
\hline \multicolumn{5}{|l|}{$\begin{array}{l}\text { Adolescent } \\
\text { mental health } \\
(\mathrm{SCL}-5)^{\mathrm{a}}\end{array}$} \\
\hline $\begin{array}{l}\text { Bottom 75\% } \\
\text { (ref.) }\end{array}$ & - & - & - & - \\
\hline Top 25\% & $0.51(0.45-0.61)$ & $1.34(1.18-1.53)$ & $0.34(0.23-0.49)$ & $1.38(1.11-1.72)$ \\
\hline No response & $0.48(0.28-0.84)$ & $1.29(0.91-1.53)$ & $0.32(0.12-0.79)$ & $1.34(0.75-2.38)$ \\
\hline \multicolumn{5}{|l|}{ Latent profiles $^{d}$} \\
\hline LP1 & $0.81(0.67-0.97)$ & $0.92(0.79-1.07)$ & $0.75(0.59-0.94)$ & $0.76(0.58-1.00)$ \\
\hline LP2 & $0.79(0.51-1.24)$ & $1.03(0.74-1.43)$ & $0.64(0.35-1.15)$ & $0.69(0.40-1.18)$ \\
\hline LP3 (ref.) & - & - & - & - \\
\hline LP4 & $1.29(0.93-1.78)$ & $1.20(0.92-1.57)$ & $1.31(0.88-1.92)$ & $1.09(0.69-1.72)$ \\
\hline LP5 & $0.56(0.28-1.14)$ & $0.91(0.54-1.53)$ & $0.48(0.20-1.15)$ & $0.57(0.26-1.23)$ \\
\hline \multicolumn{5}{|c|}{ 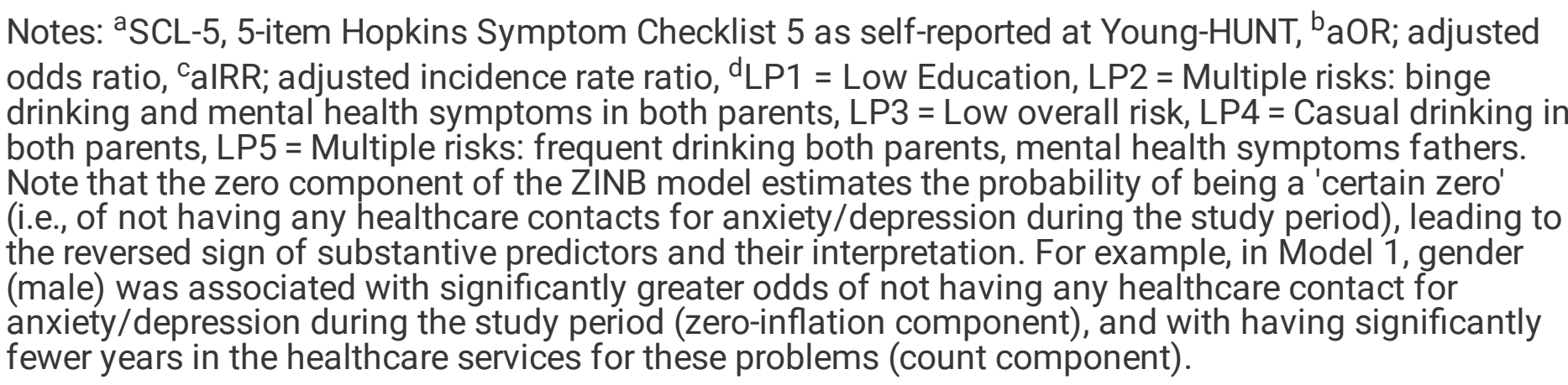 } \\
\hline
\end{tabular}




\section{Discussion}

In this study, we examined the association between parental risk constellations and offspring's recurring utilization of healthcare services for anxiety and depression disorders, as measured both by the duration of and the number of such contacts during the seven-year study period. When compared with low-risk parental constellation, no parental risk constellation was significantly associated with either the number of years offspring spent in contact with healthcare services, or the total number of contacts for anxiety/depression during the 7-year study period. The strongest predictors of these outcomes were offspring's own characteristics; specifically, elevated mental health symptoms in adolescence and gender, as would be expected given ample evidence for continuity of these mental health issues across the lifespan $(38,39)$ and greater likelihood of anxiety and depression disorders among women $(40-44)$.

Our findings thus appear aligned with the body of research reporting no major associations between parental risk factors and recurrence of anxiety or depression in offspring $(8,9)$. For instance, maternal depression was associated with subsequent onset of offspring anxiety and depression disorders, but not with the recurrence of the disorders in a large nationwide sample of US households (8), while parental depression was associated with increased risk of depression in offspring, but not with the number or duration of depressive episodes in a small longitudinal community sample (10). A set of German community studies that examined longitudinal associations between parental psychopathology and unfavorable family environments with offspring social phobia reported that parental psychopathology was associated with onset (45), but not with proportion of years affected since disorder onset (9).

Consistent with evidence from these studies, the entirety of our results also points at the salience of accumulated parental risks primarily in relation to the disorder risk itself, and less so in relation to its recurrence among offspring. Specifically, using the same sample, we have previously shown that compared with offspring in low-risk families, offspring from family constellations characterized by multiple risks - specifically, low education in both parents (LP1) and elevated frequencies and quantities of drinking in both parents, and symptoms of mental health problems in fathers (LP5) - were at greater risk of subsequently receiving a diagnosis/treatment for anxiety/depression (5). However, in the current study, offspring from family constellations characterized by multiple risks were not at greater risk for greater duration or frequency of contacts when compared to offspring from the low-risk constellation. Neither were offspring from any of the remaining constellations. Seen in conjunction with previous research (8-10) and the initial findings from this sample (5), the entirety of our results suggest that parental risks may be more informative for understanding the etiology of offspring's anxiety and depression, than they may be for understanding of their course, including recurrence of healthcare utilization.

In addition to adding to the literature by using a novel approach and providing a different perspective to the literature, there are important contextual and structural differences between our study and several of those referred to above, especially concerning access to education and healthcare. For example, in the US, where most of the previous studies were conducted, access to healthcare varies significantly, and 
parental education may play a more deciding role in the process of accessing treatment for mental health problems (46). In the US, about $30 \%$ of adolescents experience anxiety disorder; of which less than $20 \%$ receive treatment $(47,48)$. Getting access to evidenced-based care is difficult even for privileged families, more so for families from rural and low SES backgrounds (48). In Norway, education and healthcare are publicly funded and universally accessible, so all residents have equal access. Results from a Norwegian setting are consequently less prone to the usual confounders. However, access to healthcare services is not synonymous with people making use of them. Among persons diagnosed with anxiety or depression through diagnostic interviews, less than half had registry records indicating contact with primary and/or specialist healthcare services for these problems (49). In the current study, registry data do not allow us to say for sure whether the recurrence of contact reflects the severity of the disorder, but the literature on utilization of healthcare services, provides ample evidence that persons with more severe anxiety and depression are more frequent healthcare services utilizers (11-13). Taken together, our novel approachcombining health surveys and health registries- and the context where the study was conducted, strengthens the evidence suggesting that parental risk factors are linked with the risk of anxiety/depression in the first place, but not necessarily with recurrence, or severity.

\section{Methodological considerations}

Major strengths of the study include the use of person-centered approaches for identification of underlying, yet previously unknown, parental risk profiles based on information obtained from both parents. Combining health surveys and health registries to capture health care utilization for anxiety and depression, our findings substantively contribute to the knowledge base almost entirely consisting of studies utilizing a lifetime history approach or clinical interviews. Our sample included 2-parent families where offspring, mothers, and fathers participated in the HUNT survey. While this limits generalizability, this approach avoided the single data source limitations and biases as previous studies, where information about parental characteristics is provided by only the offspring alone or the offspring and one parent (22). Even though our analytical sample was highly selective, this non-representativeness does not hinder inferences regarding the prospective associations between parental risk factors and offspring's recurrence of healthcare service utilization for anxiety/depression (50).

Nevertheless, the findings should be considered within the specific context of this study, including the universal access to healthcare in Norway and combination of population-wide health registries with selfreported survey data. Both self-reports and registry data have their limitations. The first may be affected by recall bias, selective reporting, and underreporting $(51,52)$; the latter are conservative and capture only those who self-select into seeking help for, and are diagnosed with, or receive treatment $(49,53)$. Thus, while the actual rate of anxiety and depression may be higher than what is officially recorded in health registries, the current study include complete information about primary and specialist healthcare service utilization for anxiety and depression disorders. The use of registries should also increase confidence about diagnostic accuracy, which may be an issue in studies where outcomes are captured using selfreport. 


\section{Conclusion}

Parental risk constellations were not prospectively associated with recurring utilization of healthcare services for anxiety and depression disorders among the offspring during the 7-year study period; offspring from 4 risky constellations were no more likely to use such services for longer period of time or to use them on more occasions than offspring from the low-risk constellation. Seen in conjunction with the initial set of results from this sample, accumulated parental risks may be thus more informative for understanding the etiology of offspring's anxiety and depression alone, than they may be for understanding of other aspects, including recurrence of healthcare utilization in offspring.

\section{List Of Abbreviations}

alRRs - Adjusted incidence rate ratios

HADS - Hospital Anxiety and Depression Scale

HUNT - The Nord-Trøndelag Health Study

LP -Latent Profile

LPA -Latent Profile Analysis

OR -Odds Ratio

SES -Socioeconomic status

SCL-5 - Hopkins Symptom Checklist 5

YLD - Years Lived with Disability

ZINB - Zero-inflated negative binomial

\section{Declarations}

\section{Ethics declarations}

Study participants provided informed consent. The study was approved by the Norwegian Data Protection Authority (Ethics reference \# 38949) and the Regional Committees for Medical and Health Research Ethics (Ethics reference \#2014/867). All procedures were performed in accordance with the relevant guidelines and regulations of these review boards.

\section{Consent for publication}

Not applicable. 
Availability of data and materials

The datasets generated and/or analyzed during the current study are not publicly available due to legal restrictions in sharing these data.

\section{Competing interests}

The authors have no competing interests.

\section{Funding}

EY was supported by the Research Council of Norway (\#262177 and \#288083).

\section{Authors contributions}

IOL conceptualized and designed the study, interpreted results, drafted the initial manuscript, and reviewed and revised the manuscript ad assisted in analysis aspects. JBA assisted in study conceptualization and study design, designed the data analysis strategy, conducted the data analysis, assisted in drafting the initial manuscript, and reviewed and revised the manuscript. NA, SS, MH, EY and HA assisted in the study conceptualization, data integrity, and analysis aspects and critically reviewed the manuscript for important intellectual content. All authors read and approved the final version of the manuscript and agreed to be personally accountable for all aspects of the work.

\section{Acknowledgements}

We thank The Nord-Trøndelag Health Study (The HUNT Study), a collaboration between HUNT Research Centre, (Faculty of Medicine and Health Sciences, NTNU, Norwegian University of Science and Technology), Trøndelag County Council, Central Norway Regional Health Authority, and the Norwegian Institute of Public Health, for providing survey data for this study; and Statistics Norway, the Norwegian Patient Registry, and the Control and Payment of Health Reimbursements Registry for providing registry data for this study. Last, but not least, we are grateful to all the HUNT and Young-HUNT participants.

\section{Disclaimer}

Data from the Norwegian Patient Registry have been used in this publication. The interpretation and reporting of these data are the sole responsibility of the authors, and no endorsement by the Norwegian Patient Registry is intended nor should be inferred.

\section{References}

1. Kessler RC, McGonagle KA, Zhao S, Nelson CB, Hughes M, Eshleman S, et al. Lifetime and 12-month prevalence of DSM-III-R psychiatric disorders in the United States: results from the National Comorbidity Survey. Arch Gen Psychiatry [Internet]. 1994;51(1):8. Available from: http://archpsyc.jamanetwork.com/article.aspx?articleid=496456 
2. Polanczyk G V, Salum GA, Sugaya LS, Caye A, Rohde LA. Annual Research Review: A meta-analysis of the worldwide prevalence of mental disorders in children and adolescents. J Child Psychol Psychiatry. 2015;56(3):345-65.

3. Merikangas KR, He JP, Burstein M, Swanson SA, Avenevoli S, Cui L, et al. Lifetime prevalence of mental disorders in U.S. adolescents: Results from the national comorbidity survey replicationadolescent supplement (NCS-A). J Am Acad Child Adolesc Psychiatry. 2010 Oct 1;49(10):980-9.

4. Vos T, Barber RM, Bell B, Bertozzi-Villa A, Biryukov S, Bolliger I, et al. Global, regional, and national incidence, prevalence, and years lived with disability for 301 acute and chronic diseases and injuries in 188 countries, 1990-2013: A systematic analysis for the Global Burden of Disease Study 2013. Lancet [Internet]. 2015 Aug 22 [cited 2020 Aug 14];386:743-800. Available from: http://www.thelancet.com/article/S0140673615606924/fulltext

5. Lund IO, Skurtveit S, Handal M, Bukten A, Ask Torvik F, Ystrøm E, et al. Association of Constellations of Parental Risk With Children's Subsequent Anxiety and Depression Findings From a HUNT Survey and Health Registry Study. JAMA Pediatr. 2019;

6. McLaughlin KA, Green JG, Gruber MJ, Sampson NA, Zaslavsky AM, Kessler RC. Childhood adversities and adult psychiatric disorders in the national comorbidity survey replication II: Associations with persistence of DSM-IV disorders. Arch Gen Psychiatry. 2010 Feb 1;67(2):124-32.

7. McLaughlin KA, Breslau J, Green JG, Lakoma MD, Sampson NA, Zaslavsky AM, et al. Childhood socio-economic status and the onset, persistence, and severity of DSM-IV mental disorders in a US national sample. Soc Sci Med. 2011 Oct 1;73:1088-96.

8. Kessler RC, Davis CG, Kendler KS. Childhood adversity and adult psychiatric disorder in the US National Comorbidity Survey. Psychol Med. 1997 Sep;27(5):1101-19.

9. Knappe S, Beesdo K, Fehm L, Höfler M, Lieb R, Wittchen HU. Do parental psychopathology and unfavorable family environment predict the persistence of social phobia? J Anxiety Disord. 2009 Oct $1 ; 23(7): 986-94$.

10. Weissman MM, Wickramaratne P, Nomura Y, Warner V, Pilowsky D, Verdeli H. Offspring of depressed parents: 20 years later. Am J Psychiatry. 2006;

11. Kujanpää T (Tero. Generalized anxiety disorder and health care utilization. University of Oulu; 2016.

12. Chiu M, Saxena FE, Kurdyak P, Wilton AS, Vigod SN. Health Service Use among Individuals with Depression and Psychological Distress: A Population-Based Cohort Study in Ontario, Canada: https://doi.org/101177/0706743720927826 [Internet]. 2020 May 27 [cited 2020 Aug 5]; Available from: https://journals.sagepub.com/doi/abs/10.1177/0706743720927826

13. Birnbaum HG, Kessler RC, Kelley D, Ben-Hamadi R, Joish VN, Greenberg PE. Employer burden of mild, moderate, and severe major depressive disorder: Mental health services utilization and costs, and work performance. Depress Anxiety [Internet]. 2010 Jan 1 [cited 2020 Aug 5];27(1):78-89. Available from: https://onlinelibrary.wiley.com/doi/full/10.1002/da.20580

14. Holst C, Schurmann Tolstrup J, Sørensen J, Sofie V, Pisinger C, Becker U. Parental alcohol use disorder with and without other mental disorders and offspring alcohol use disorder Running title: 
Alcohol use disorder and mental disorders.

15. Rutter M, Quinton D. Parental psychiatric disorder: effects on children. Psychol Med. 1984;14(4):853-80.

16. Amone-P'Olak K, Burger H, Ormel J, Huisman M, Verhulst FC, Oldehinkel AJ. Socioeconomic position and mental health problems in pre- and early-adolescents: The trails study. Soc Psychiatry Psychiatr Epidemiol. 2009;44:231-8.

17. Green JG, McLaughlin KA, Berglund PA, Gruber MJ, Sampson NA, Zaslavsky AM, et al. Childhood adversities and adult psychiatric disorders in the national comorbidity survey replication I: Associations with first onset of DSM-IV disorders. Arch Gen Psychiatry. 2010 Feb 1;67(2):113-23.

18. Pisinger VSC, Bloomfield K, Tolstrup JS. Perceived parental alcohol problems, internalizing problems and impaired parent - child relationships among 71988 young people in Denmark. Addiction [Internet]. 2016 Nov 1 [cited 2020 Nov 30];111(11):1966-74. Available from: http://doi.wiley.com/10.1111/add.13508

19. Cuijpers P, Langendoen Y, Bijl R V. Psychiatric disorders in adult children of problem drinkers: prevalence, first onset and comparison with other risk factors. Addiction [Internet]. 1999 Oct 1 [cited 2020 Nov 30];94(10):1489-98. Available from: http://doi.wiley.com/10.1046/j.13600443.1999.941014895.x

20. Mahedy L, Hammerton G, Teyhan A, Edwards AC, Kendler KS, Moore SC, et al. Parental alcohol use and risk of behavioral and emotional problems in offspring. PLoS One. 2017;

21. Christoffersen MN, Soothill K. The long-term consequences of parental alcohol abuse: a cohort study of children in Denmark. J Subst Abuse Treat [Internet]. 2003;25(2):107-16. Available from: http://ac.els-cdn.com/S0740547203001168/1-s2.0-S0740547203001168-main.pdf?_tid=ad96d47246c6-11e3-937d-00000aacb35d\&acdnat=1383730668_8870f2a164f4f8d91bdeb8b5bfec6ce7

22. Rossow I, Lambert F, Keating P, McCambridge J. Parental drinking and adverse outcomes in children a scoping review of cohort studies. Drug Alcohol Rev. 2015;

23. Lund IO, Bukten A. Harm to Others from Substance Use and Abuse: The Underused Potential in Nationwide Registers. Subst Abus Res Treat [Internet]. 2015;9(Suppl 2):33-8. Available from: http://www.ncbi.nlm.nih.gov/pubmed/26560694

24. Krokstad S, Langhammer A, Hveem K, Holmen TL, Midthjell K, Stene TR, et al. Cohort Profile: the HUNT Study, Norway. Int J Epidemiol [Internet]. 2012/08/11. 2013;42(4):968-77. Available from: http://ije.oxfordjournals.org/content/42/4/968.full.pdf

25. Holmen TL, Bratberg G, Krokstad S, Langhammer A, Hveem K, Midthjell K, et al. Cohort profile of the Young-HUNT Study, Norway: a population-based study of adolescents. Int J Epidemiol [Internet]. 2013/02/06. 2013;43(2):536-44. Available from: http://ije.oxfordjournals.org/content/43/2/536

26. Holmen J, Midthjell K, Krüger Ø, Langhammer A, Holmen TL, Bratberg GH, et al. The Nord-Trøndelag Health Study 1995-97 (HUNT 2): objectives, contents, methods and participation. Nor Epidemiol. 2003;13(1):19-32. 
27. Langhammer A, Krokstad S, Romundstad P, Heggland J, Holmen J. The HUNT study: Participation is associated with survival and depends on socioeconomic status, diseases and symptoms. BMC Med Res Methodol. 2012;

28. Leiknes, Kari Ann, Dalsbø, Therese Kristine, Siqueland J. 2016 Måleegenskaper ved den norske versjonen av Hospital Anxiety and Depression Scale (HADS) Psykometrisk vurdering. Oslo, Norway: Folkehelseinsitituttet; 2016.

29. Stordal E, Bjartveit Krüger M, Dahl NH, Krüger O, Mykletun A, Dahl AA. Depression in relation to age and gender in the general population: The Nord-Trøndelag health study (HUNT). Acta Psychiatr Scand [Internet]. 2001 Sep 1 [cited 2020 Aug 4];104(3):210-6. Available from:

https://onlinelibrary.wiley.com/doi/full/10.1034/j.1600-0447.2001.00130.x

30. Lanza ST, Rhoades BL. Latent Class Analysis: An Alternative Perspective on Subgroup Analysis in Prevention and Treatment. Prev Sci. 2013;14:157-68.

31. Collins LM, Lanza ST. Latent Class and Latent Transition Analysis with Applications in the Social, Behavioral, and Health Sciences. John Wiley \& Sons. 2010.

32. Strand BH, Dalgard OS, Tambs K, Rognerud M. Measuring the mental health status of the Norwegian population: A comparison of the instruments SCL-25, SCL-10, SCL-5 and MHI-5 (SF-36). Nord J Psychiatry. 2003;57(2):113-8.

33. Burdzovic Andreas J, Ask Torvik F, Lund IO. Prospective associations between parents' alcohol use patterns and the risk of high-school dropout among boys and girls: A combined HUNT survey and educational registry study. Accept Publ Psychol Addict Behav. 2021;

34. Elhai JD, Calhoun PS, Ford JD. Statistical procedures for analyzing mental health services data. Psychiatry Res. 2008;160(2):129-36.

35. Gardner W, Mulvey EP, Shaw EC. Regression Analyses of Counts and Rates: Poisson, Overdispersed Poisson, and Negative Binomial Models. Psychol Bull. 1995;118(3):392-404.

36. StataCorp. Stata Statistical Software: Release 15. College Station, TX: StataCorp LLC; 2017.

37. Williams RL. A note on robust variance estimation for cluster-correlated data. Biometrics. 2000.

38. Visser JH, Van Der Ende J, Koot HM, Verhulst FC. Predicting change in psychopathology in youth referred to mental health services in childhood or adolescence. J Child Psychol Psychiatry Allied Discip [Internet]. 2003 May 1 [cited 2020 Feb 26];44(4):509-19. Available from: http://doi.wiley.com/10.1111/1469-7610.00140

39. Costello EJ, Mustillo S, Erkanli A, Keeler G, Angold A. Prevalence and development of psychiatric disorders in childhood and adolescence. Arch Gen Psychiatry. 2003 Aug 1;60(8):837-44.

40. Salk RH, Hyde JS, Abramson LY. Gender differences in depression in representative national samples: Meta-analyses of diagnoses and symptoms. Psychol Bull [Internet]. 2017 Aug 1 [cited 2021 Feb 4];143(8):783-822. Available from: /fulltext/2017-18894-001.html

41. Wichstrøm L. The emergence of gender difference in depressed mood during adolescence: the role of intensified gender socialization. Dev Psychol [Internet]. 1999 [cited 2021 Feb 4];35(1):232-45. Available from: / fulltext/1998-03083-019.html 
42. Weissman MM, Klerman GL. Sex Differences and the Epidemiology of Depression. Arch Gen Psychiatry [Internet]. 1977 Jan 1 [cited 2021 Feb 4];34(1):98-111. Available from: https://jamanetwork.com/

43. McLean CP, Asnaani A, Litz BT, Hofmann SG. Gender differences in anxiety disorders: Prevalence, course of illness, comorbidity and burden of illness. J Psychiatr Res. 2011 Aug 1;45(8):1027-35.

44. Harris MG, Baxter AJ, Reavley N, Diminic S, Pirkis J, Whiteford HA. Gender-related patterns and determinants of recent help-seeking for past-year affective, anxiety and substance use disorders: Findings from a national epidemiological survey. Epidemiol Psychiatr Sci [Internet]. 2016 Dec 1 [cited 2021 Feb 4];25(6):548-61. Available from: https://www.cambridge.org/core/journals/epidemiologyand-psychiatric-sciences/article/abs/genderrelated-patterns-and-determinants-of-recent-helpseekingfor-pastyear-affective-anxiety-and-substance-use-disorders-findings-from-a-national-epidemiologicalsurvey/6B422980E5083568AC8026F825C34853

45. Knappe S, Lieb R, Beesdo K, Fehm L, Low NCP, Gloster AT, et al. The role of parental psychopathology and family environment for social phobia in the first three decades of life. Depress Anxiety [Internet]. 2009 Apr 1 [cited 2020 Mar 11];26(4):363-70. Available from: http://doi.wiley.com/10.1002/da.20527

46. Corrigan PW, Watson AC. The stigma of psychiatric disorders and the gender, ethnicity, and education of the perceiver. Community Mental Health Journal. 2007.

47. Merikangas KR, He JP, Burstein M, Swendsen J, Avenevoli S, Case B, et al. Service utilization for lifetime mental disorders in U.S. adolescents: Results of the national comorbidity surveyAdolescent supplement (NCS-A). J Am Acad Child Adolesc Psychiatry. 2011 Jan 1;50(1):32-45.

48. Allen KB, Benningfield M, Blackford JU. Childhood Anxiety-If We Know So Much, Why Are We Doing So Little? JAMA Psychiatry [Internet]. 2020 May 13 [cited 2020 May 20]; Available from: https://jamanetwork.com/journals/jamapsychiatry/fullarticle/2765962

49. Torvik FA, Ystrom E, Gustavson K, Rosenström TH, Bramness JG, Gillespie N, et al. Diagnostic and genetic overlap of three common mental disorders in structured interviews and health registries. Acta Psychiatr Scand. 2018;137:54-64.

50. Rothman KJ, Gallacher JEJ, Hatch EE. Why representativeness should be avoided. Int J Epidemiol. 2013;42:1012-4.

51. Haugland SH, Holmen TL, Krokstad S, Sund ER, Bratberg GH. Intergenerational hazardous alcohol use and area factors: the HUNT Study, Norway. Subst Use Misuse. 2015;50(14):1753-64.

52. Johnson TP. Sources of Error in Substance Use Prevalence Surveys. Int Sch Res Not. 2014;2014.

53. Kendler KS, Ji J, Edwards AC, Ohlsson H, Sundquist J, Sundquist K. An extended Swedish national adoption study of alcohol use disorder. JAMA Psychiatry. 2015;72(3):211-8. 